\title{
Kronik Hastalık Öz Yönetim Ölçeğinin Türkçe Geçerlilik Güvenilirliği
}

\author{
Turkish Validity and Reliability of the Chronic Disease Self-Management Scale
}

\author{
Yunus Emre Öztürk ${ }^{1}$ (D) Müjdat Yeşildal ${ }^{* 1}$ (D) Özer Arık ${ }^{\text {(D) }} \quad$ Yunus Fidan $^{3}$ \\ ${ }^{1}$ Department of Health Management, Selcuk University, Konya, Turkey \\ 2 Health Services Vocational School, Necmettin Erbakan University, Konya, Turkey \\ ${ }^{3}$ Faculty of Dentistry, Mersin University, Mersin, Turkey
}

Received: 18.08.2021

Accepted: 28.09 .2021

This article was checked by intihal.net

Öz

Bu çalışmanın amacı Kronik Hastalık Öz Yönetim Ölçeğinin Türkçe uyarlamasını yaparak, geçerlilik ve güvenilirliğini incelemektir. Metodolojik tipte tasarlanan bu araştırmanın örneklemi çevrimiçi yöntem ile ulaşılan 244 kronik hastadan oluşmaktadır. Verilerin toplanmasında demografik veri formu ve Ngai ve arkadaşları tarafından geliştirilen Kronik Hastalık Öz Yönetim Ölçeği kullanılmıştır. Ölçeğin geçerliği faktör analizi ve kapsam geçerliği ile güvenirliği ise madde-toplam puan korelasyonu, iç tutarlılık ve test tekrar test yöntemleri ile analiz edilmiştir. Yapılan analizler sonucunda kapsam geçerliliği değerlendirme puanları ile uzman görüşleri arasında istatistiksel olarak fark olmadığı tespit edilmiştir. Faktör analizi sonucunda açıklanan toplam varyans \%65,30 olarak bulunurken dört faktörlü orijinal yapı korunduğu görülmüştür. Ölçme aracı kendini damgalama, tedavi uyumu, damgalamayla baş etme ve sağlık bakım etkinliği alt boyutlarından oluşmaktadır. Ölçeğin alt boyutlarında Cronbach Alpha katsayıları 0,789 - 0,876 arasındadır. Test - tekrar test korelasyon katsayısı r=0,87 olarak tespit edilmiştir. Elde edilen bulgular Kronik Hastalık Öz Yönetim Ölçeğinin Türkçe uyarlamasının geçerli ve güvenilir olduğuna karar verilmiştir.

Anahtar Kelimeler: Damgalama, Kronik Hastalık Öz Yönetim, Sağlık Bakım Etkinliği, Tedavi Uyumu

\section{Abstract}

The aim of this study is to analyze the validity and reliability of the Chronic Disease Self-Management Scale by adapting it to Turkish. The sample of this study, which was designed in methodological type, consists of 244 chronic patients who were reached by online method. Demographic data form and Chronic Disease Self-Management Scale developed by Ngai et al. were used to collect data. The validity of the scale was analyzed by factor analysis, content validity and reliability, item-total score correlation, internal consistency and test-retest methods. As a result of the analyzes made, it was determined that there was no statistical difference between the content validity evaluation scores and the expert opinions. As a result of factor analysis, the total variance explained was found to be $65.30 \%$, while the original structure with four factors was preserved. The measurement tool consists of self-stigma, treatment compliance, coping with stigma, and health care effectiveness sub-dimensions. The Cronbach Alpha coefficients in the sub-dimensions of the scale range from 0.789 to 0.876 . The test-retest correlation coefficient was determined as $r=0.87$. Findings: It has been decided that the Turkish version of the Chronic Disease Self-Management Scale is valid and reliable.

Keywords: Chronic illness self-management, Health maintenance efficacy, Stigma, Treatment adherence

Öztürk, Y. E., Yeşildal, M., Arık, Ö. \& Fidan, Y. (2021). Kronik Hastalık Öz Yönetim Ölçeğinin Türkçe Geçerlilik Güvenilirliği. Journal of Academic Value Studies, 7(3), 375-381. http://dx.doi.org/10.29228/javs.52376

\footnotetext{
${ }^{*}$ E-mail address: mujdatyesildal@gmail.com (Corresponding author)
} 


\section{Giriş}

Kronik hastalıklar, genel olarak bir yıl veya daha uzun süren, sürekli tıbbi müdahale gerektiren veya günlük yaşam aktivitelerini veya her ikisini sınılayan durumlar olarak tanımlanır (CDC, 2020). Kalp hastalığı, kanser ve diyabet gibi kronik hastalıklar, küresel hastalık yükünün yarısından fazlasını oluşturmaktadır (Benziger vd., 2016). Önde gelen ölüm nedenleri olarak, 2012 yılında dünyadaki 56 milyon ölümün 38 milyonundan (\%68) kronik hastalıklar sorumludur (WHO, 2014). Türkiye'deki ölümlerin \%87,5'i kronik hastalık kaynaklıdır (Kontsevaya vd., 2014). Kronik bir hastalıkla yaşamak, hastalığın etkilerini azaltmak ve hastalığın ilerlemesini sınırlamak için kendi kendini yönetmeyi gerektirmektedir (Clark vd., 1991). Bir hasta kendi hastalığının kendi kendine tedavisine aktif olarak dâhil olursa, hasta sağlık sonuçlarının önemli ölçüde iyileşeceğine dair birçok gösterge vardır (Garcia vd., 2019). Hasta sorumluluğunu vurgulayan kendi kendine yönetim, kronik hastalıkları hafifletmede ve tedavi etmede eğitimin ötesine geçerek bireylere hastalıklarıyla ilgili zorlukları aktif bir şekilde belirleme ve çözme konusunda destek vermektedir (Grady ve Gough, 2014). Kronik hastalar, hastalıkları hakkında günlük kararlar verirler ve kendi kendilerini idare etme eğilimdedirler. Öz yönetim, hastaların kronik durumlarıyla mümkün olan en iyi yaşam kalitesine ulaşmayı desteklemektedir. Öz yönetimi öğrenen hastalar, problemleri çözmeyi başardıklarında öz-yeterlikleri artar (Bodenheimer vd., 2002; Perez-Benzo vd., 2020).

Öz yönetim eğitimi programları ile hastaların semptomlarını yönetme, uyku alışkanlıklarını iyileştirme, stresi azaltma ve sağlıklı bir yaşam tarzı sürdürme için gerekli becerileri kazanması sağlanabilir (CDC,2020). Kronik hastalığı olan hastaları, reçeteli ilaç uyumu, uygun bir diyet planı takip etme ve egzersiz yapma gibi sağık davranışlarının kendi kendine yönetimi için teşvik etmenin ve desteklemenin, hastalık semptomlarını azaltmada ve sağlık ve refahı iyileştirmede yararlı olduğu kanıtlanmıştır (Lederle ve Blitzer, 2019). Bireylerin kronik hastalıkları ile ilgili olarak hastalıklarını daha iyi yönetme ve sağlık hizmetlerini algılama konusunda duyarlı olmaları gerekir. Bu durumda sağık okuryazarlığı ve hastanın iradesini artırmak halk sağlığı stratejisi açısından önem oluşturmaktadır (Ko v d.,2018; Lopezlopez vd., 2021). Bu hastalıkların sağıık hizmetleri sistemleri üzerinde önemli bir etkisi vardır, çünkü hastalar sağık hizmeti kaynaklarının sık kullanıcılarıdır ve durumlarını bir ömür boyu yönetmek için genellikle karmaşık müdahaleler ve tedaviye intiyaç duyarlar (Wu vd., 2020). Hastalar, kişisel duygularla ilgili değerlerle (kendi kendine yönlendirme ve sağlıklı olma) veya yaşam koşullarıyla (sağlıklı bir yaşam tarzı ve finansal dengeyi sürdürme) ilgili değerlerle öz bakım için motive edilebilir (Karimi ve Clark, 2016). Özellikle öz bakım konusunda aile üyeleri tarafından sağlanan katkılar, hastaların ilaç tedavisine uyumunu iyileştirebilir, sağlıklı yaşam tarzı davranışlarını teşvik edebilir ve acil servis kullanımını azaltabilmektedir (lovino, vd., 2020). Küresel düzeyde artan yaygınlığı önemli bir sağlık sorunu haline gelen kronik hastalıkların kendi kendine yönetimi, hastaların yaşam kalitesini iyileştirmede destekleyici bir unsurdur (Ngai vd., 2020). Bu bağlamda, kronik hastalığı olan bireylerin hastalıklarını yönetme düzeylerinin tespit edilmesi önem oluşturmaktadır.

Bu araştırmanın amacı 2020 yılında Ngai ve diğerleri tarafından geliştirilen Kronik Hastalık Öz Yönetim Ölçeğinin Türkçe geçerlilik ve güvenilirlik çalışmasını yapmaktır.

\section{Gereç ve Yöntem}

Metodolojik tipte tasarlanan bu araştırmada örneklem büyüklüğünün belirlenmesinde madde sayısının 10 katı yeterli görülmektedir (Alpar, 2016; Tavşancıl, 2005). Bu bağlamda ölçme aracında 23 madde bulunduğu dikkate alınırsa en az 230 kişilik bir örneklem araştırma için yeterli sayılabilecektir. Araştırma kapsamında 244 kişinin verileri kullanılmıştır. Araştırmada kolayda örnekleme yöntemi ile toplanan veriler kullanılmıştır.

Veri toplama formunda, temel demografik bulgular için araştırmacılar tarafından hazırlanan soru formu ve Ngai ve diğerleri (2020) tarafından geliştirilen Kronik Hastalık Öz Yönetim Ölçeği kullanılmıştır. Orijinal ölçek Kendini Damgalama (7 madde), Damgalamayla Baş Etme (5 madde), Sağlık Bakım Etkinliği (5 madde) ve Tedavi Uyumu ( 6 madde) olmak üzere 4 alt boyut ve 23 maddeden oluşmaktadır. Ölçeğin alt boyutlarına ait Cronbach Alpha katsayısı 0,715 0,879 arasındadır. Ölçme aracında maddelerin derecelendirilmesi 1= Asla 2= Nadiren 3=Ortalama 4= Oldukça sık, 5= Her Zaman şeklinde yapılmaktadır. Veriler çevrimiçi veri toplama yöntemlerinden Google Formlar aracılığıyla Nisan Mayıs 2021 tarihlerinde toplanmıştır. Kronik hastalık sahibi bireylere sosyal medya grupları aracılığıyla ulaşılmıştır. Ölçme aracı alanında uzman altı çevirmen tarafından Türkçeye çevrilmiştir. Çeviri işlemi sonucunda psikometrik özelliklerini (maddelerin anlaşıırlık, basitlik ve konuyla ilişkisini belirlemeye yönelik) incelenmesi on dört öğretim üyesi tarafından yapılmıştır. Ifadelere son hali verildikten sonra 35 kişiyle ön uygulama gerçekleştirilmiştir. Ön uygulama sonucunda anlaşılmayan maddeler tekrar kontrol edilerek verilerin toplanması aşamasına geçilmiştir.

Araştırma kapsamında toplanan veriler düzeltme işlemi sonrası SPSS 26.0 ve SPSS AMOS 24.0 programları kullanılarak analiz edilmiştir. Demografik değişkenler için tanımlayııı istatistik yöntemlerinden sıkık ve yüzdelik 
kullanılmıştır. Alan uzmanı hekim akademisyenlerin maddeleri değerlendirmesinde kapsam geçerlilik indeksi ve Kendall uyuşum katsayısı (KW) kullanılmıştır. Geçerlilik ve güvenilirlik çalışmalarında ilk aşama olarak açımlayııı faktör analizi (AFA) ikinci aşama doğrulayıcı faktör analizi (DFA) yapılarak güvenilirlik analizi iç tutarlıık katsayısı Cronbach Alpha ile tespit edilmiştir. Ölçeğin zamana göre değişmezliğini ölçmek için katılımcılardan 20 gün arayla toplanan veriler ile test tekrar test yapılarak Pearson Korelasyon katsayısı ile hesaplanmıştır. İstatistiksel anlamlılık düzeyi olarak $p<0,05$ alınmıştır. Uyarlama aşamasından önce ölçek geliştiren yazardan elektronik posta ile izin alınmıştır. Selçuk Üniversitesi Sağlık Bilimleri Fakültesi Girişimsel Olmayan Klinik Araştırmalar Etik Kurulundan etik kurul izni alınmıştır (Tarih: 31.03.2021, Karar no: 2021/231). Ayrıca veri toplama öncesinde katılımcılara bilgilendirilmiş gönüllü olur formu sunulmuş araştırmaya katılmayı onaylayanların verileri kullanılmıştır. Araştırma Helsinki Deklarasyonu Prensipleri'ne uygun olarak gerçekleştirilmiştir.

\section{Bulgular}

Araştırmaya katılanların \%34,8'i 46 yaş ve üzerinde olup \%58,2'si erkek, \%77,5'i evli iken \%34,8'i 3500 Türk lirası ve altında aylık gelire sahiptir. Katılımcıların \%29,9’u kronik obstrüktif akciğer hastasıdır (Tablo 1).

Tablo 1. Temel demografik bulgular.

\begin{tabular}{|c|c|c|c|}
\hline \multicolumn{2}{|l|}{ Özellikler (n=244) } & $n$ & $\%$ \\
\hline \multirow{3}{*}{ Yaş } & 35 ve altı & 84 & 34,4 \\
\hline & $36-45$ & 75 & 30,7 \\
\hline & 46 ve üzeri & 85 & 34,8 \\
\hline \multirow{2}{*}{ Cinsiyet } & Erkek & 142 & 58,2 \\
\hline & Kadın & 102 & 41,8 \\
\hline \multirow{2}{*}{ Medeni Durum } & Evli & 189 & 77,5 \\
\hline & Bekar & 55 & 22,5 \\
\hline \multirow{3}{*}{ Gelir Durumu } & 3500 TL ve altı & 85 & 34,8 \\
\hline & $3501-5500 \mathrm{TL}$ & 82 & 33,6 \\
\hline & 5501 TL ve üzeri & 77 & 31,6 \\
\hline \multirow{5}{*}{ Kronik Hastalık } & Artritler & 55 & 22,5 \\
\hline & Diyabet & 48 & 19,7 \\
\hline & $\mathrm{KOAH}$ & 73 & 29,9 \\
\hline & $\mathrm{HT}$ & 37 & 15,2 \\
\hline & Diğer & 31 & 12,7 \\
\hline
\end{tabular}

Ölçek maddelerinin kapsam geçerlilik indeksi ve Kendall W katsayısı kullanılarak hesaplanmıştır. Uzmanlardan her bir maddenin kapsam ve dil yönünden uygunluğunu $1-4$ arasında bir puan ile derecelendirmeleri istenilmiştir. Kapsam geçerliliği değerlendirme puanları ile uzman görüşleri arasında istatistiksel olarak fark olmadığı tespit edilmiştir $(K W=0,114 ; p>0,05)$.

Ölçek geçerlilik ve güvenilirlik çalışmalarında madde toplam puan korelasyon değerleri 0,50 ve altında olan değerlerin farklı bir niteliği ölçtüğünü göstermektedir (Erdoğan vd, 2015; Özdamar, 2017). Tedavi Uyumu alt boyutu 1. madde ve Sağlık Bakım Etkinliği 1. madde toplam puan korelasyon değeri 0,50'den küçük olduğu için çıkarılarak AFA yapılmıştır. AFA öncesinde örneklem yeterliliğini ölçmek için Kaiser-Meyer-Olkin ve Bartlett Küresellik Testi yapılmıştır. Örneklem ölçüm yeterliliği çok iyi olarak bulunmuştur $(\mathrm{KMO}=0,835)$. Bartlett Küresellik Testi anlamlı bulunmuştur $\left(x^{2}=2688,73 ; s d=210 ; p<0,001\right)$. Faktör analizi sonucunda ölçeğin alt boyutları; Kendini Damgalama \%21,64 Tedavi Uyumu \%18,93 Damgalamayla Baş Etme \%12,92 Sağlık Bakım Etkinliği \%11,79 olmak üzere açıklanan toplam varyans $\% 65,30$ olarak bulunurken dört faktörlü orijinal yapı korunmuştur (Tablo 2).

Tablo 2. Faktörlere ayrılmış madde yükleri.

\begin{tabular}{|l|l|l|l|l|}
\hline \multirow{2}{*}{ Maddeler } & \multicolumn{4}{|l|}{ Alt Boyutlar } \\
\cline { 2 - 5 } & KD & TU & DBE & SBE \\
\hline KD4 & 0,843 & & & \\
\hline KD2 & 0,833 & & & \\
\hline KD5 & 0,828 & & & \\
\hline
\end{tabular}




\begin{tabular}{|l|l|l|l|l|}
\hline KD1 & 0,788 & & & \\
\hline KD6 & 0,715 & & & \\
\hline KD3 & 0,683 & & & \\
\hline KD7 & 0,660 & & & \\
\hline TU2 & & 0,824 & & \\
\hline TU5 & & 0,823 & & \\
\hline TU3 & & 0,817 & & \\
\hline TU4 & & 0,758 & & \\
\hline TU6 & & 0,719 & & \\
\hline DBE2 & & & 0,794 & \\
\hline DBE3 & & & 0,769 & \\
\hline DBE4 & & & 0,716 & \\
\hline DBE1 & & & 0,616 & \\
\hline DBE5 & & & 0,497 & \\
\hline SBE4 & & & & 0,818 \\
\hline SBE5 & & & & 0,791 \\
\hline SBE2 & & & & 0,664 \\
\hline SBE3 & & & & 0,622 \\
\hline Özdeğer & & 3,97 & 2,71 & 2,47 \\
\hline Varyans & 18,93 & 12,92 & 11,79 \\
\hline Toplam Varyans & 65,30 & & & \\
\hline KD: Kendini Damga & & & & \\
\hline
\end{tabular}

KD: Kendini Damgalama, TU: Tedavi Uyumu, DBE: Damgalamayla Baş Etme SBE: Sağlık Bakım Etkinliği

AFA sonucunda elde edilen yapıya SPSS AMOS programı kullanılarak DFA yapılmıştır. Analiz sonucunda uyum iyiliğini değerlerin iyileştirmek için; DBE1 - DBE2, SBE3 - SBE4 ve SBE4 - SBE5 maddeleri arasında kovaryans yapılarak tekrardan DFA yapılmıştır (Şekil 1). DFA sonucunda uyum iyiliği değerleri CMIN/df = 1,975; RMSEA =0,043; GFI = 0,952; TLI = 0,959 değerleri iyim uyum göstermiş ve model istatistiksel olarak anlamlı bulunmuştur ( $p<0,001)$ (Altunışık vd., 2005; Karagöz, 2016).

Şekil 1. Kronik hastalık öz yönetim ölçeğini oluşturan ifadelere ilişkin path grafiği.

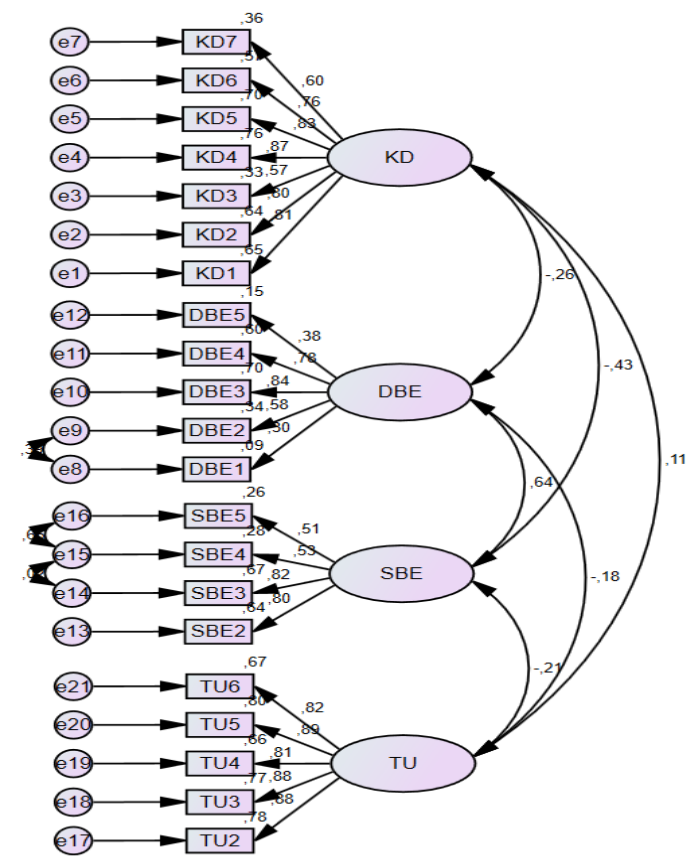

KD: Kendini Damgalama, TU: Tedavi Uyumu, DBE: Damgalamayla Baş Etme SBE: Sağlık Bakım Etkinliği 
Ölçme aracı taslak formu 20 gün arayla aynı gruba uygulanmıştır. Elde edilen ortalama puanlar ile korelasyon analizi yapılmıştır $(r=0,87)$. Test - tekrar test korelasyon katsayısının yüksek çıkması ölçme aracının zamana göre değişmediğini göstermektedir (Erdoğan vd., 2015). Ölçeğin madde toplam puan korelasyon katsayıları 0,62 - 0,82 arasında olduğu ve pozitif yönde anlamlı bir ilişki tespit edilmiştir. Güvenilirlik analizi kapsamında Cronbach Alpha kullanılmıştır. Ölçeğin alt boyutlarının Cronbach Alpha katsayıları 0,789-0,876 arasında bulunmuştur (Tablo 3).

\section{Tablo 3. Kronik hastalık öz yönetim ölçeği madde korelasyon analizi}

\begin{tabular}{|c|c|c|c|}
\hline \multicolumn{2}{|c|}{ Kronik Hastalık Öz Yönetim Ölçeği } & $\begin{array}{l}\text { Madde Toplam } \\
\text { Korelasyonu }\end{array}$ & $\begin{array}{l}\text { Cronbach } \\
\text { Alpha }\end{array}$ \\
\hline \multirow{7}{*}{ 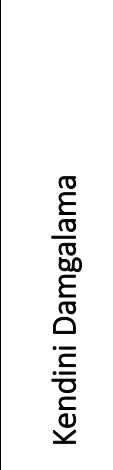 } & 1. Hastalığımdan dolayı sosyal ortamlarda utanç duyarım & 0,636 & \multirow{7}{*}{0,876} \\
\hline & 2. Hastalığımdan dolayı kendimi diğerlerinden farklı hissediyorum & 0,687 & \\
\hline & 3. Hastalığımdan dolayı başkalarına yük olmaktan endişe duyarım & 0,781 & \\
\hline & 4. Hastalığımdan dolayı diğerlerine karşı yabancılaşmış hissediyorum & 0,625 & \\
\hline & 5. Hastalığımdan dolayı başkalarının düşüncelerinden endişe duyuyorum & 0,820 & \\
\hline & 6. Hastalığımdan bahsetmemek için arkadaş edinmekten kaçınıyorum & 0,763 & \\
\hline & 7.Hastalığımın belirtileri karşısında şaşırıyorum & 0,716 & \\
\hline \multirow{5}{*}{ 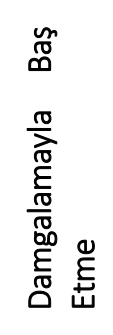 } & 1.Üzgün hissetmekten kaçınabilirim. & 0,611 & \multirow{5}{*}{0,850} \\
\hline & 2.Kötü düşünceleri durdurabilir ve kendimi sinirlendirmekten kaçınabilirim. & 0,697 & \\
\hline & 3.Durumu nasıl iyileştireceğimi planlayabilir ve harekete geçebilirim & 0,769 & \\
\hline & 4.Neyin değiştirilebileceğini veya değiştirilemeyeceğini kavrayabilirim. & 0,620 & \\
\hline & 5.Arkadaşlarımdan ve ailemden destek isteyebilirim & 0,617 & \\
\hline \multirow{4}{*}{ 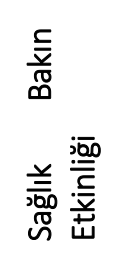 } & 1.Kendi sağ ığımı yönetebiliyorum & 0,758 & \multirow{4}{*}{0,820} \\
\hline & 2.Kendime iyi bakabilirim. & 0,619 & \\
\hline & 3. Hastalığım hakkında net bilgiye sahibim & 0,673 & \\
\hline & 4.Tedavi yöntemi hakkında net bilgiye sahibim & 0,717 & \\
\hline \multirow{5}{*}{ 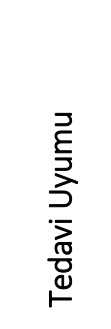 } & 1.illacı/tedaviyi unutur veya ihmal ederim. ${ }^{*}$ & 0,602 & \multirow{5}{*}{0,789} \\
\hline & 2.Meşgul olduğum zaman ilaç almayı veya tedaviyi hatırlamakta zorlanırım* & 0,684 & \\
\hline & 3.Kontrol için doktorun önerdiği zamanı unutuyor veya görmezden geliyorum* & 0,693 & \\
\hline & 4.Okulda, işte veya dışarıdayken ilaçları almayı aksatıyorum* & 0,680 & \\
\hline & 5.Illacı almak/tedavi olmak için başkasının hatırlatmasına ihtiyaç duyuyorum* & 0,621 & \\
\hline
\end{tabular}

* Ters kodlanan madde.

\section{Tartışma ve Sonuç}

Bu çalışmada Kronik Hastalık Öz Yönetim Ölçeğinin Türk dil ve kültürel yapısına uygun şekilde geçerlilik ve güvenilirlik testleri yapılmıştır.

Geliştirilen ölçeğin yeni bir dile uygun olup olmadığını test etmek için yapı ve kapsam geçerliliği yapılmalıdır (Karakoç ve Dönmez, 2014). Farklı bir dilde geliştirilen ölçeğin yeni bir dile uyarlanması dil geçerliliği olarak tanımlanmaktadır (Seçer, 2018) Alanında uzman kişilerin ölçeğe ait her maddeyi dil ve kültürel açıdan uygunluğunu derecelendirerek KW katsayısı hesaplandı. KW katsayısının 0,05 değerinden yüksek olması maddelerin uzman derecelendirilmesinin uyumlu olduğunu göstermektedir. 
Kapsam geçerlilik aşaması sonucunda yapı geçerliliğini test etmek için AFA ve DFA yapıldı. Faktör analizi öncesinde örneklem büyüklüğünü ve faktör analizine uygunluğu test etmek amacıyla KMO ve Bartlett Küresellik Testi yapıldı. KMO katsayısı 0,83 olması örneklem yeterliliğinin çok iyi olduğunu göstermektedir (Kalaycı, 2018). Bartlett Küresellik Testi anlamlı bulunması ölçeğin faktör analizi için uygun olduğunu göstermektedir.

Açıklanan toplam varyans oranının çok boyutlu ölçeklerde \%50'nin üzerinde olması gerekmektedir (Gürbüz ve Şahin, 2018). Açımlayııı faktör analizi sonucunda ölçeğin dört faktörlü orijinal yapısını koruduğu tespit edildi. Kronik Hastalık Öz Yönetim Ölçeğinin dört faktörlü yapısının toplam varyansın \%65,30’ u açıkladığı bulunmuştur.

AFA'dan sonra ortaya çıkan yapının doğrulayıcı faktör analizi ile test edilmesi amaçlanmıştır. Uyarlama çalışmalarında DFA özgün yapının yeni toplanan veriler ile doğrulanıp doğrulanmadığını tespit etmek amacıyla kullanıır (Gürbüz ve Şahin, 2018). Bu analiz ile ölçeğin ve faktörlerin yeniden değerlendirmesi yapılmaktadır. Doğrulayıcı faktör analizinde analiz süreci AFA gibi gözlenen değişkenlerin bir setiyle başlar ve faktörler altında daha küçük bir sayı kullanılarak değişkenler arasındaki ilişki açıklanmaya çalışılır (Çelik ve Yılmaz, 2016). Yirmi bir maddeden oluşan yapıyı doğrulamak için kurulan ölçüm modeli analiz sonucunda 21 madde 4 alt boyut ile doğruladığı görülmüştür. Ölçeğin orijinalindeki yapının Türk katılımcılarda doğrulanıp doğrulanmadığını belirlemek için DFA sonucu uyum indeksi değerlerinden $\mathrm{CMIN} / \mathrm{df}=1,975 ; \mathrm{RMSEA}=0,043 ; \mathrm{GFI}=0,952 ; \mathrm{TLI}=0,959$ değerleri iyi uyum göstererek doğrulandığı tespit edilmiştir (Babahanoğlu ve Daşbaş, 2021; Kalaycı, 2018; Seçer, 2018).

Ölçeğin güvenirliğinin hesaplanmasında Cronbach Alpha güvenirlik katsayısı, madde toplam korelasyonu ve test tekrar test yöntemi kullanılmıştır. Cronbach Alpha güvenirlik katsayısının 1'e yakın olması ve bu sayının 0,6 değerinden daha büyük değerlerin dikkate alınması önerilmektedir (Gürbüz ve Şahin, 2018; Karagöz, 2016). Araştırmada ölçeğin alt boyutlarının Cronbach Alpha katsayıları Kendini Damgalama 0,876 Tedavi Uyumu 0,850 Damgalamayla Baş Etme 0,820 Sağlık Bakım Etkinliği 0,789 olarak tespit edilmiştir. Literatür ile karşılaştırıldığında ölçeğin yüksek derecede güvenilir olduğunu göstermektedir (Gürbüz ve Şahin, 2018; Karagöz, 2016). Test tekrar test analizi ile ölçeğin tekrarlayan uygulamalarda tutarlı olması ve zamana göre değişmezliği incelenmektedir (Kaya ve Maimaiti, 2018). Araştırmada ölçek literatüre uygun olarak iki hafta arayla uygulanmıştır. Korelasyon katsayısının yüksek çıkması ölçme aracının zamana göre değişmediğini göstermektedir.

Yapılan araştırma sonucunda Kronik Hastalık Öz Yönetim ölçeğinim Türkiye' de kronik hastalıklara sahip bireylerin hastalık öz yönetim becerilerini belirlemek için yapılan çalışmalarda 4 alt boyuttan oluşan 21 maddeli haliyle kullanılabilir. Ölçeğin özel seçilmiş örneklemler ile de test edilmesi uygun olabilir.

\section{Kaynaklar}

Alpar, R. Spor, Sağlık ve Eğitim Bilimlerinden Örneklerle Uygulamalı İstatistik ve Geçerlik-Güvenirlik. Ankara, Detay Yayıncllik;2016

Altunısık, R., Coşkun, R., Bayraktaroğlu, S., Yıldırım, E. Sosyal Bilimlerde Araştırma Yöntemleri SPSS Uygulamalı. Adapazarı: Sakarya Kitabevi;2005

Babahanoğlu, R, Daşbaş, S. Madde kullanımı damgalama mekanizması ölçeği: geçerlilik ve güvenirlik çalışması. Toplum ve Sosyal Hizmet, 2021;32 (1), 141-172. dol: 10.33417/tsh.798982

Benziger CP, Roth GA, Moran AE. (2016) The Global Burden of Disease Study and the Preventable Burden of NCD. Glob Heart. 2016;11(4):393-397. doi: 10.1016/j.gheart.2016.10.024.

Bodenheimer T, Lorig K, Holman H, Grumbach K. Patient self-management of chronic disease in primary care. JAMA. Nov 2002;20;288(19):2469-75. doi: 10.1001/jama.288.19.2469.

Centers for Disease Control and Prevention (2020). About chronic illness. https://www.cdc.gov/chronicdisease/about/index.htm. (Erişim Tarihi: 07 Ocak 2021).

Clark, N. M., Becker, M. H., Janz, N. K., Lorig, K., Rakowski, W., Anderson, L. Self-Management of Chronic Disease by Older Adults: A Review and Questions for Research. J.Aging Health, 1991;3(1), 327. https://doi.org/10.1177/089826439100300101

Clark, N. M., Becker, M. H., Janz, N. K., Lorig, K., Rakowski, W., Anderson, L. self-management of chronic disease by older adults: a review and questions for research. J.Aging Health, 1991; 3(1), 3-27. https://doi.org/10.1177/089826439100300101 
Çelik, H. E., \& Yılmaz, V. LISREL 9.1 ile Yapısal Eşitlik Modellemesi: Temel Kavramlar-Uygulamalar-Programlama. Ankara, Anı Yayıncılık; 2016.

Erdoğan S., Nahcivan N. ve Esin N. Hemşirelikte Araştırma (2. Baskı). Ankara Nobel Kitabevi;2015

García L., Tomás, J. Parra L,. Lloret J. An m-health application for cerebral stroke detection and monitoring using cloud services, Int J Inf Manage, 2019;45, 319-327, https://doi.org/10.1016/j.ijinfomgt.2018.06.004.

Grady, P. A., \& Gough, L. L. (2014). Self-management: a comprehensive approach to management of chronic conditions. AJPH, 2014;104(8), e25-e31. https://doi.org/10.2105/AJPH.2014.302041

Gürbüz, Ş., Şahin, F. Sosyal Bilimlerde Araştırma Yöntemleri 5. Baskı. Ankara,Seçkin Yayıncılık;2018.

Iovino, P., Lyons, KS., De Maria, M., Vellone, E., Ausili, D., Lee, CS., Riegel, B., Matarese, M. Patient and caregiver contributions to self-care in multiple chronic conditions: A multilevel modelling analysis. IJNS, 2020;116,103574. https://doi.org/10.1016/j.ijnurstu.2020.103574

Kalaycı Ş. SPSS Uygulamalı Çok Değişkenli İstatistik Teknikleri. Ankara: Dinamik Akademi Yayınları; 2018.

Karagöz, Y. SPSS 23 ve AMOS 23 uygulamalı istatistiksel analizler. Ankara, Nobel Akademik Yayıncılık;2016

Karakoç A, Dönmez P. Ölçek Geliştirme Çalışmalarında Temel Illkeler. Tıp Eğitimi Dünyası. 2014; 13(40): 39-49.

Karimi, M., Clark, A. M. How do patients' values influence heart failure self-care decision-making?: A mixed-methods systematic review. International journal of nursing studies, 2016;59, 89-104. https://doi.org/10.1016/j.ijnurstu.2016.03.010

Kaya, Ş. D. \& MaiMaiti, N. Ayaktan hasta memnuniyeti ölçeği geliştirme çalışması. Hacettepe Sağlık İdaresi Dergisi, 2018;21(4), 601-623.

Ko D, Bratzke LC, Roberts T. Self-management assessment in multiple chronic conditions: A narrative review of literature. Int J Nurs Stud. 2018;Jul;83:83-90. doi: 10.1016/j.ijnurstu.2018.04.009..

Kontsevaya, A., Farrington, J., Balcılar, M., \& Ergüder, T. (2018). Prevention and control of noncommunicable diseases in Turkey.

Lederle M, Bitzer EM. A close look at lay-led self-management programs for chronic diseases and health care utilisation: A systematic review and meta-analysis. Ger Med Sci. 2019. doi: 10.3205/000269.

López-López, L., Ariza-Mateos, MJ., Rodríguez-Torres, J., Cabrera-Martos, I., Granados-Santiago, M., Torres-Sánchez, I., Valenza, MC. Results of a self-management program added to standard physical therapy in chronic neck pain. PEC, 2021;104(6), 1438-1444.

Ngai, SSY., Cheung, CK., Ng, YH., Tang, HY., Ngai, HL., Wong, KHC. Development and validation of the chronic illness selfmanagement (CISM) scale: Data from a young patient sample in Hong Kong. Children and Youth Services Review, 2020;114-105077. https://doi.org/10.1016/j.childyouth.2020.105077.

Özdamar, K. Ölçek ve Test Geliştirme Yapısal Eşitlik Modellemesi IBM SPSS, IBM SPSS AMOS ve MINITAB Uygulamalı. Eskişehir: Nisan Kitabevi;2017.

Perez-Benzo, GM., Muellers, K., Chen, S., Liu, B., Bagiella, E., O'Conor, R., Wolf, MS., Wisnivesky, J.P., Federman, AD. Identifying Behavioral Phenotypes in Chronic Illness: Self-Management of COPD and Comorbid Hypertension. Patient Educ. Couns..2020, https://doi.org/10.1016/j.pec.2020.08.025

Seçer i. Psikolojik Test Geliştirme ve Uyarlama süreci. SPSS ve Lisrel uygulamaları. 2. Baskı. Ankara: Anı Yayıncılık; 2018.

Tavşancıl E. Tutumların Ölçülmesi ve SPSS ile Veri Analizi. Ankara, Nobel Yayıncılık;2005

World Health Organization. Global status report on noncommunicable diseases 2014 (No. WHO/NMH/NVI/15.1).

Wu, LC., Lai, CY., Huang, CJ., Chou, FH., Yu, ET, Yu, CY. Psychological distress and diabetes self-management in patients with type 2 diabetes and comorbid serious mental illness. APN, 2020;34(4), 218-223. https://doi.org/10.1016/j.apnu.2020.04.013 